\title{
The compatibility of single and combined applications of the entomopathogenic nematode, Heterorhabditis indica with imidacloprid against red palm weevil, Rhynchophorus ferrugineus (Oliv.)
}

\author{
Aqsa Arshad1,2, Asim Munawar*1,3, Muhammad Ishaque Mastoi4, Samar Sohail5, Faiza Bashir², Chengjuan Liang ${ }^{3,6}$ \\ ${ }^{1}$ Department of Entomology, University of Agriculture, Faisalabad, Pakistan \\ ${ }^{2}$ Department of Zoology, College of Basic Sciences, University of Narowal, Punjab, Pakistan \\ ${ }^{3}$ Institute of Insect Sciences, College of Agriculture and Biotechnology, Zhejiang University, China \\ ${ }^{4}$ Plant Sciences Division, Pakistan Agricultural Research Council, PARC, Islamabad, Pakistan \\ ${ }^{5}$ Insitute of Horticulture, University of Agriculture Faisalabad, Pakistan \\ ${ }^{6}$ Institute of Applied Ecology, Fujian Agriculture and Forestry University, China
}

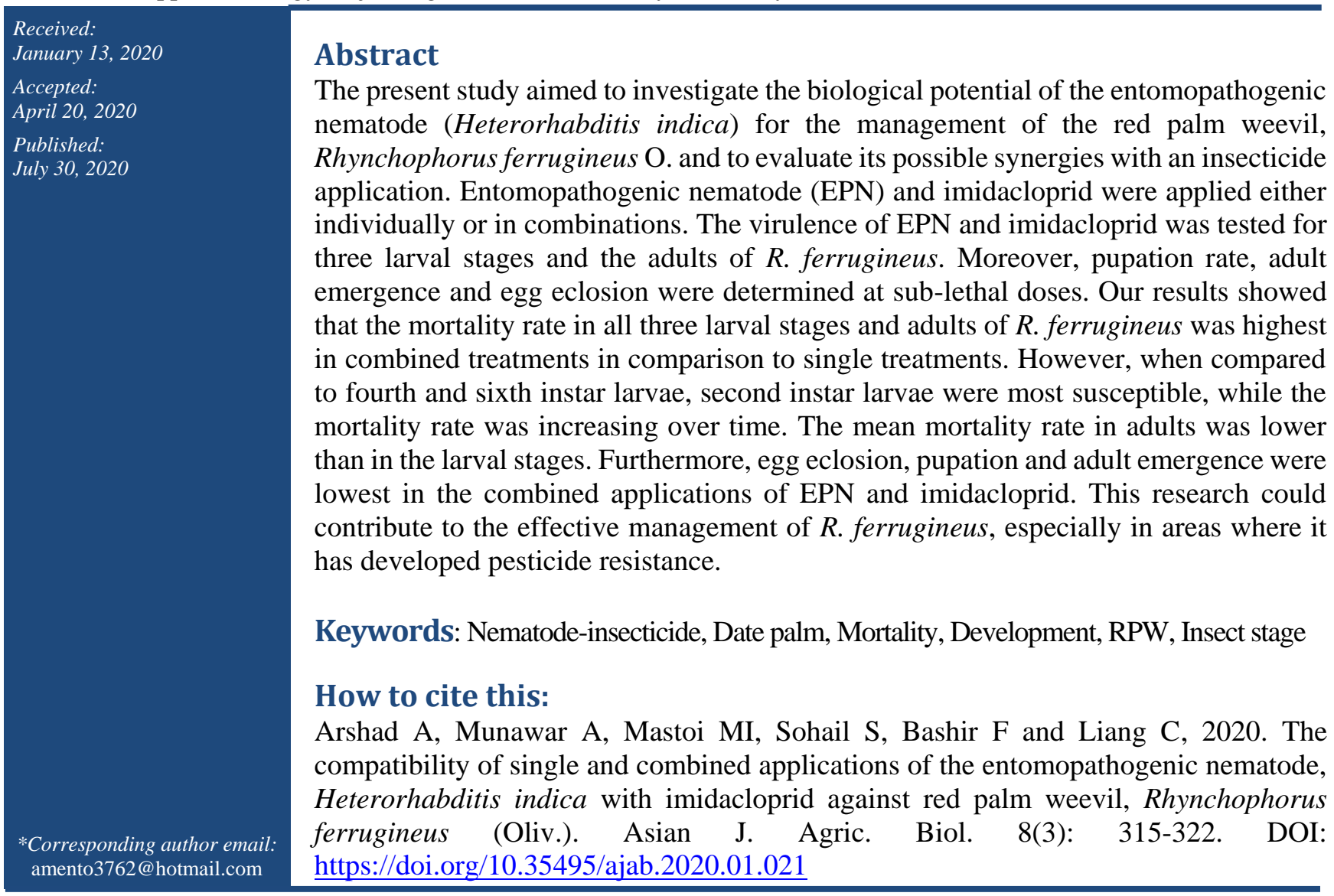

This is an Open Access article distributed under the terms of the Creative Commons Attribution 3.0 License. (https://creativecommons.org/licenses/by/3.0), which permits unrestricted use, distribution, and reproduction in any medium, provided the original work is properly cited.

\section{Introduction}

Date palm (Phoenix dactylifera L.) is the most important crop worldwide, especially in Arab countries where it has been used as a staple food (Gaugler 1988; Erskine et al., 2004). Date palm trees show a high diversity in texture, chemical composition, color, and shape, depending on the 
environment, seasonal effects, genotypes and cultivation methods (Hadrami and Jameel, 2012). Many coleopteran pests attack date palm trees. Among them, the red palm weevil (RPW), $R$. ferrugineus (Olivier, 1970), has been identified as the most notorious pest (Wakil et al., 2015; Dembilio and Jaques, 2015).

This pest is posing a severe threat to the date palm production and it is also known as the coconut weevil, Asiatic palm weevil, hidden enemy, red stripe weevil, and AIDS of date palm due to the slow death of infected trees (Khamiss and Abdel, 2013). This pest has a complex nature, damaging trees that are younger than 20 years (Nirula, 1956; Abraham et al., 1998). The weevil larvae feed within the tree trunk, damage the vascular system by mining into the heart of the trees, which results in the collapse of the tree (Ju et al., 2011). Fully matured grubs pupate within the chewed up frass for 11-40 days. Under unfavorable conditions and without control measures, the date palm tree dies within 6-8 months (Kurian and Mathen, 1971; Avand, 1996; Rajamanickam et al., 1995).

To manage this severe pest, date palm growers have, for many decades used fumigants, as well as insecticides. However, chemical applications have become a significant challenge for palm growers due to the complex nature of RPW (Hussain et al., 2013). Moreover, insecticide applications are not only potentially harmful to the environment and human health but also promote insecticide resistance in RPW. (Abraham et al., 1998). Alternative biological control agents such as entomopathogenic nematodes and its combination with chemicals could provide a significant breakthrough for the management of RPW (Khan et al., 2012; Charnley and Collins, 2007; De Faria and Wraight, 2007).

Entomopathogenic nematodes (EPNs) have proven to be efficient and potent microbial control agents against a variety of pests, especially against insect pests of stored grain (Dembilio et al., 2010). However, so far, very few studies have investigated the combined effect of EPNs with pesticides under laboratory as well as under field conditions (Dembilio et al., 2010; Rovesti and Deseo, 1990; Portman et al., 2016; Yan et al., 2012). Many scientists working in this area of research have successfully used EPNs for RPW control. EPNs are most effective as compare to others microbial control agents, kill the insect by damaging their cuticle instead of ingestion and can quickly transfer from one insect to another (Atwa, 2018; Lacey and Georgis, 2012; Pervez et al., 2012;
Yadav and Lalramliana, 2012). EPNs are obligate parasites mainly from the family of Heterorhabditidae and Steinernematidae. They kill insects with the help of mutualistic bacteria that live in their intestines (Poinar, 1990). EPNs are considered safe and less dangerous in pesticide applications to non-target organisms, environment, and human health as well as can be integrated with each other's, often showing potent synergistic and additive interactions (Thurston et al., 1994).

The objective of the current study was to investigate the potential of EPNs applications for the effective control of RPW, especially in combination with chemicals. Development, growth, and mortality of RPW were examined under laboratory conditions followed by treatments with the EPN, Heterorhabditis indica, or the insecticide alone and in combination. The obtained results could be helpful in decision making for the choice of suited treatments and application times during oncoming future research trials. This research will lead to successful and environmentally safe management control of RPW existence in date palm trees and their hosts.

\section{Material and Methods}

\section{Insect collection}

Adults of the red palm weevil, $R$. ferrugineus, were collected from different districts of Punjab, Pakistan from infested date palm trees. All stages of RPW were collected in separate boxes closed with rubber bands. Collected insects were fed with fresh pieces of a date palm during the collection.

\section{Insect rearing}

Collected insects were brought to the laboratory where they were supplied with clean and fresh food to increase their population. In the absence of a date palm, sugarcane was used as an alternative host. The insects were provided with optimal conditions; $27 \pm 4^{\circ} \mathrm{C}$ and $65 \%$ relative humidity. Both males and females were kept together to harvest eggs. Eggs hatched after 4 to 5 days and first instar larvae were collected. The diet was changed at regular intervals.

\section{Nematode culture}

We used nematodes from our laboratory culture reared on the wax moth Galleria mellonella L. Larvae killed by nematodes were placed on white traps for harvesting. Emerging IJ stages of nematodes were collected. Collected nematodes were transferred to Petri dishes, 
Aqsa Arshad et al.

wrapped with parafilm and stored at $10^{\circ} \mathrm{C}$.

\section{Pesticide}

The insecticide used in our experiments was obtained from the company Bayer Crop Science, Pvt. Ltd. Pakistan. The chemical was labeled with all pieces of information, including active ingredients. The required formulation was produced following the instructions provided.

\section{Bioassay tests}

\section{Against RPW larvae}

Small plastic cups were used for our bioassay tests. For each treatment, $15 \mathrm{RPW}$ larvae were inoculated with two different concentrations of nematodes (50IJ and 100IJ) and were placed in cups filled with sterilized sand. The cups were closed with cotton wools. A camel hairbrush was used to inoculate the nematodes. For the insecticide treatments, two different concentrations (1ppm and 2ppm) of imidacloprid were poured on filter papers and placed within cups filled with sterilized sand. Fifteen larvae were placed in each cup. A micropipette was used to apply the insecticide to the filter papers. Each treatment was replicated three times. Three bioassay tests were performed to check RPW larval mortality after 7, 14 and 21 days. Larvae that were showing slow movement or were unable to move were counted as dead. The environmental conditions were the same, as mentioned in the rearing section. The same method was applied to test for the combined effect of the nematodes with the insecticide.

\section{Against RPW larvae development}

In this trial, we tested the combined effect of the nematodes and the insecticide on the development of RPW and evaluated the egg eclosion, pupation and adult emergence of RPW. The nematode was applied to the RPW larvae with a camel hairbrush and placed in cups filled with sterilized sand. For the insecticide treatments, RPW larvae were dipped into the imidacloprid solution (1ppm and 2ppm) for ten seconds and placed in cups with sterilized sand. The diet provided to the test insects was also treated with an imidacloprid solution with different concentrations. Mortality data were collected until adult emergence. The same method was used to test for the combined effect of the nematode and the insecticide. The whole experiment was repeated three times.

\section{Against RPW adults}

In this trial, we measured the mortality of adult RPWs in response to nematode and insecticide application and their combination. Adults of RPW were treated with different nematode concentrations applied with a camel hairbrush. For the insecticide tests, sugarcane pieces $(10 \mathrm{~mm})$ were first dipped into two different imidacloprid concentrations for one minute and then offered to RPW adults. After 48 hours of feeding, the treated sugarcane pieces were replaced by new, untreated ones. In the combined treatments, sugarcane pieces treated with imidacloprid were offered to RPW adults for 48 hours and then after 24 hours of time intervals, the same adults were treated with the nematodes. Ten adults were used in each treatment and each treatment was replicated three times. Adult mortality was recorded after 7,14 and 21 days.

\section{Statistical analysis}

The mortality data were analyzed using Abbot's Formula. To test for significant differences among treatments, larval and adult mortality was analyzed with an Analysis of Variance (ANOVA). Corrected mortality was calculated using Abbot's formula. The differences among means were calculated using Tukey's HSD test at a $5 \%$ level. Excel sheet was used for descriptive analysis.

\section{Results}

\section{Efficacy of EPN and insecticide against $R$. ferrugineus larvae}

The mortality rate under different concentrations of EPN and imidacloprid was observed. In the first week of exposure, imidacloprid showed the highest mortality rate against $R$. ferrugineus, which was significantly lower in the nematode treatment. The mortality of $R$. ferrugineus was evaluated in three different larval stages (second, fourth and sixth). The mortality rate in the combined treatment was gradually decreasing, with a maximum of $59.36 \pm 1.97$, in the second instar larvae and with $49.52 \pm 1.57$ and $45.39 \pm 2.07$ in the fourth and sixth instars, respectively. Our results show that the combined efficacies of nematodes and insecticide directly depend on the larval stage. The same treatment was applied to all stages; the developmental stage of the RPW was positively correlated with its ability to cope with the insecticide-nematode treatment (Table 1). 
Aqsa Arshad et al.

Table-1. Mean mortality of red palm weevil, $R$. ferrugineus larvae treated with two different concentrations of $\boldsymbol{H}$. Indica and Imidacloprid under different time intervals

\begin{tabular}{|c|c|c|c|c|c|c|c|c|c|}
\hline & k 1 & & - & Week 2 & & & Week 3 & & \\
\hline $\mathbf{T r}$ & & $4^{\text {th }} i$ & $6^{\text {th }}$ instar & & star & $6^{\text {th }}$ inst & & $4^{\text {th }}$ instar & $6^{\text {th }}$ instar \\
\hline & & & & & & & & & $20 \mathrm{f}$ \\
\hline & & & & & & 16. & & 24. & $68 \mathrm{f}$ \\
\hline & & & $\mathrm{de}$ & & & & & & \\
\hline & & 32.2 & & & & 37.4 & & 42. & $77 \mathrm{~d}$ \\
\hline & $46 \mathrm{~b}$ & 60 & $\mathrm{bc}$ & $4 d$ & $4 \mathrm{~b}$ & 4576 & $7 \mathrm{~b}$ & 53.3 & 48.0 \\
\hline & & 39.1 & Jav & & & & & 58.57 & $53.23 \pm 2.21 \mathrm{c}$ \\
\hline & & $42.72 \pm 1.63 \mathrm{~b}$ & & & & & & $74.39 \pm 1.91 \mathrm{a}$ & $62.45 \pm 2.47 \mathrm{~b}$ \\
\hline$\times \mathbf{H}$ & $.36 \pm 1.97 \mathrm{a}$ & $49.52 \pm 1.57 \mathrm{a}$ & $45.39 \pm 2.07 \mathrm{a}$ & $0.53 \pm 2.28 \mathrm{a}$ & $72.17 \pm 2.06 \mathrm{a}$ & $66.67 \pm 2.08 \mathrm{a}$ & $37.25 \pm 1.72 a$ & $78.94 \pm 2.10 \mathrm{a}$ & $72.69 \pm 1.9$ \\
\hline
\end{tabular}

Means showing different letters in each column are significantly different at a 5\% level $(P<0.05$, Tucky HSD test).Hi: Heterorhabditis indica; I: Imidacloprid; IJ: Infective Juvenile

Nematodes usually have a slow mode of action to kill herbivores insects; however, when they are combined with insecticides, they become more productive and fastest to kill.

After the second and third weeks of the exposure, the mortality rate was much higher than in the first week. It can also be an indication that time is an essential factor for the efficacy of nematode applications.

\section{Efficacy of EPN and insecticide against $R$. ferrugineus adults}

To test our hypothesis, the effectiveness of the nematodes and their combinations with the insecticide were also tested against adult RPW (Table 2).

Table-2. Mean mortality of $\boldsymbol{R}$. ferrugineus adults treated with two different concentrations of $\boldsymbol{H}$. Indica and Imidacloprid under different time intervals

\begin{tabular}{|l|c|c|c|}
\hline Treatments & Week 1 & Week 2 & Week 3 \\
\hline Hi1 (50IJ) & $5.55 \pm 2.94 \mathrm{e}$ & $11.23 \pm 1.99 \mathrm{e}$ & $21.36 \pm 2.47 \mathrm{~g}$ \\
\hline Hi2 (100IJ) & $8.89 \pm 2.60 \mathrm{e}$ & $13.58 \pm 1.61 \mathrm{e}$ & $28.27 \pm 2.02 \mathrm{fg}$ \\
\hline I1 (1ppm) & $14.57 \pm 2.39 \mathrm{de}$ & $21.60 \pm 1.09 \mathrm{~d}$ & $33.70 \pm 2.32 \mathrm{ef}$ \\
\hline I2 (2 ppm) & $20.25 \pm 2.23 \mathrm{~cd}$ & $32.27 \pm 1.74 \mathrm{~cd}$ & $41.85 \pm 2.23 \mathrm{de}$ \\
\hline $\mathbf{I} \mathbf{\text { Hi1}}$ & $27.16 \pm 2.20 \mathrm{bc}$ & $36.08 \pm 2.04 \mathrm{c}$ & $47.78 \pm 1.74 \mathrm{~cd}$ \\
\hline $\mathbf{I} \times \mathbf{H i 2}$ & $31.73 \pm 1.84 \mathrm{ab}$ & $39.15 \pm 1.78 \mathrm{~b}$ & $54.44 \pm 1.9 \mathrm{bc}$ \\
\hline $\mathbf{I} \mathbf{2} \times \mathbf{H i 1}$ & $33.83 \pm 2.60 \mathrm{ab}$ & $42.72 \pm 2.47 \mathrm{~b}$ & $61.24 \pm 2.43 \mathrm{~b}$ \\
\hline $\mathbf{I} 2 \times \mathbf{H i} 2$ & $41.97 \pm 1.78 \mathrm{a}$ & $49.52 \pm 1.25 \mathrm{a}$ & $73.58 \pm 1.73 \mathrm{a}$ \\
\hline
\end{tabular}

Means showing different letters in each column are significantly different at a 5\% level $(P<0.05$, Tucky HSD test). Hi: Heterorhabditis indica; I: Imidacloprid; IJ: Infective Juvenil

The adults were treated in the same way as the larvae with regard to the application of the insecticide and the nematodes. Our results showed that the mortality rate in $R$. ferrugineus adults was lower than in the larval stages. Under individual treatments of nematode and insecticide, the $R$. ferrugineus showed lowest adults mortality $(8.89 \pm 2.60$ and $20.25 \pm 2.23)$, which was recorded higher $(16.40 \pm 1.89$ and $38.25 \pm 2.03)$ in larval stages.

The mortality rate for the insecticide treatment was higher than for the nematode treatment. The mortality rate was gradually increasing with increasing concentration being highest in the combined treatment. In the combined treatment, the maximum mortality was $41.97 \pm 1.78$ after the first week of exposure and it steadily increased to $49.52 \pm 1.25$ and $73.58 \pm 1.73$ after the second and third weeks, respectively. Overall, the mortality was lowest in the adults in comparison to larval stages.

Efficacy of EPN and insecticide against $R$. ferrugineus development

The results for the impact of the different treatments on egg eclosion, pupation rate and adult emergence are summarized in Table 3.

For these trials, we used the same concentrations and treatments as for the larvae and adults in the previous section. Second, fourth, and sixth instar larvae were selected to test the impact of nematodes and their combinations with the insecticide on pupation, egg eclosion, and adult emergence. Based on our findings, pupation rate, egg eclosion and adult emergence were highest in the nematode applications than in the insecticide. The development of the larvae was decreasing with increasing nematode and insecticide concentration. In the combined treatments, the developmental rate of $R$. ferrugineus was being reduced in comparison to the single treatments. Under the combination of treatments, the second instar larvae showed lowest pupation rate, egg eclosion, and adult emergence $(4.44 \pm 1.76,00.00 \pm 0.00$ and $00.00 \pm 0.00$ ), respectively. However, in the fourth instar larvae, pupation rate and adult emergence were slightly increased but egg eclosion was continuously observed lowest. 
Aqsa Arshad et al.

Table-3. Adult emergence, pupation and egg eclosion of $R$. ferrugineus larvae treated with two different concentrations of $\boldsymbol{H}$. Indica and Imidacloprid under different insect stages.

\begin{tabular}{|c|c|c|c|c|c|c|c|c|c|}
\hline & $2^{\text {nd }}$ Instar & & - & $4^{\text {th }}$ Instar & & & $6^{\text {th }}$ instar & & \\
\hline Treatments & $\begin{array}{c}\text { Pupation } \\
(\%)\end{array}$ & $\begin{array}{c}\text { Adult } \\
\text { emergence } \\
(\%)\end{array}$ & $\begin{array}{c}\text { Egg } \\
\text { eclosion } \\
(\%) \\
\end{array}$ & $\begin{array}{c}\text { Pupation } \\
(\%)\end{array}$ & $\begin{array}{c}\text { Adult } \\
\text { emergence } \\
(\%)\end{array}$ & $\begin{array}{c}\text { Egg eclosion } \\
(\%)\end{array}$ & $\begin{array}{c}\text { Pupation } \\
(\%)\end{array}$ & $\begin{array}{c}\text { Adult } \\
\text { emergence } \\
(\%)\end{array}$ & losion \\
\hline Hil & $6 a$ & $54.44 \pm 1.98 \mathrm{a}$ & $45.31 \pm 2.08 \mathrm{a}$ & $\mathrm{d}$ & $62.35 \pm 2.00 \mathrm{a}$ & 54.4 & 73.8 & $64.69 \pm 1.92 \mathrm{a}$ & $2.23 \mathrm{a}$ \\
\hline Hi2 (100IJ) & $55.58 \pm 1.98 \mathrm{a}$ & $45.43 \pm 1.55 b$ & $33.95 \pm 2.14 b$ & $65.80 \pm 1.90 \mathrm{ab}$ & $54.32 \pm 2.34 \mathrm{~b}$ & $45.18 \pm 2.49 b$ & $63.46 \pm 2.15 b$ & $61.36 \pm 1.43 \mathrm{a}$ & $49.75 \pm 2.66 \mathrm{~b}$ \\
\hline I1 (1 & $17 \mathrm{~b}$ & $.06 \pm 2.17 \mathrm{c}$ & $.25 \pm 2.2$ & 66 & $.97 \pm 1.78 \mathrm{c}$ & $36.29=$ & 59.01 & $51.11 \pm 1.45 \mathrm{~b}$ & $41.97 \pm 1.78 \mathrm{bc}$ \\
\hline I2 ( 2 & $61 \mathrm{~b}$ & $24.94=$ & $12.35 \pm 2.21 \mathrm{~d}$ & $78 \mathrm{c}$ & 34.07 & 30 & $74 \mathrm{c}$ & $45.30 \pm 2.67 \mathrm{~b}$ & $2.61 \mathrm{~cd}$ \\
\hline I1 $\times$ Hi1 & $22.59 \pm 2.12 \mathrm{c}$ & $15.56 \pm 2.94 \mathrm{e}$ & $00.00 \pm 0.00 \mathrm{e}$ & $32.84 \pm 2.04 \mathrm{~cd}$ & $22.72 \pm 1.41 \mathrm{e}$ & $21.11 \pm 1.11 \mathrm{~d}$ & $41.85 \pm 2.23 \mathrm{~d}$ & $32.72 \pm 2.51 \mathrm{c}$ & $25.56 \pm 1.76 \mathrm{de}$ \\
\hline I1 $\times$ Hi2 & $14.57 \pm 2.39 \mathrm{~cd}$ & $.32 \pm 2.51 \mathrm{f}$ & $00.00 \pm 0.00 \mathrm{e}$ & $4.81 \pm 2.83 \mathrm{de}$ & $15.80 \pm 1.66 \mathrm{ef}$ & $14.44 \pm 1.76 \mathrm{de}$ & $31.73 \pm 1.84 \mathrm{e}$ & $21.36 \pm 2.48 \mathrm{~d}$ & $17.78 \pm 1.47 \mathrm{ef}$ \\
\hline $12 \times$ & lde & O0f & $0 \mathrm{e}$ & 16 & 12.22 & e & 23 & 15.56 & 12. \\
\hline $\mathrm{I} 2 \times \mathrm{Hi} 2$ & $4.44 \pm 1.76 \mathrm{e}$ & $00.00 \pm 0.00 \mathrm{f}$ & $00.00 \pm 0.00 \mathrm{e}$ & $11.11 \pm 2.61 \mathrm{f}$ & $6.67 \pm 1.67 \mathrm{~g}$ & $00.00 \pm 0.00 \mathrm{f}$ & $14.57 \pm 2.39 \mathrm{f}$ & $7.78 \pm 1.47 \mathrm{e}$ & $3.33 \pm 1.67 \mathrm{~g}$ \\
\hline$d f$ & 9 & 9 & 9 & 9 & 9 & 9 & 9 & 9 & 9 \\
\hline$P$ & $<0.01$ & $<0.01$ & $<0.01$ & $<0.01$ & $<0.01$ & $<0.01$ & $<0.01$ & $<0.01$ & $<0.01$ \\
\hline
\end{tabular}

Means showing different letters in each column are significantly different at a 5\% level $(P<0.05$, Tucky HSD test). Hi: Heterorhabditis indica; I: Imidacloprid; IJ: Infective Juvenile

For the sixth instar, all three parameters were slightly increased, showing that time was a significant and most crucial factor for the control of red palm weevil, $R$. ferrugineus in all treatments. The second instar stage was the most susceptible in comparison to the fourth and sixth instar stages. Nematode and insecticide concentrations and their compatibility were also significant parameters for the mortality and development of $R$. ferrugineus.

\section{Discussion}

Due to multiple and excessive applications of pesticides for the control of herbivores communities, some pests have become able to resist these control measures due to changes in their internal mechanisms such as increasing their immunity levels (Dermauw et al., 2018; Delnat et al., 2019). Researchers are challenged to find effective control strategies that should not only be safe to the environment but should also effectively kill insect pests populations without causing resistance effects (Alvarez et al., 2019; Ali et al., 2019; Allan, 2018).

Due to global warming and climate change, researchers are struggling to develop biological control strategies for the most severe insect pests to reduce the use of chemicals (Bakera et al., 2020). EPNs mainly belong to the families heterorhabditidae and Steinernematidae are the most important and safe biological control agents due to their specificity, infectivity and their non-target effects. Many researchers have combined EPNs with insecticides to improve their effectiveness, which has proven successful (Garriga et al., 2019; Yuksel et al., 2019). The red palm weevil, $R$. ferrugineus, is the most important and noxious pest of palm trees, affecting palm production worldwide (Yan et al., 2019). The management of this pest is broadly based on insecticides applications (Mashal and Obeidat, 2019).

Under these circumstances, our research aimed to evaluate the efficacies of EPN and insecticide applications - singly and in combinations - against larval and adult stages of RPW. Besides this, we also assessed their effects on the development of $R$. ferrugineus. Our results showed that larval mortality was gradually increasing with increasing concentration and time. In single treatments, imidacloprid treated larvae showed the highest mortality rate in all larval stages, which was lower in the EPN. Maximum mortality was found in the combination treatments of EPN and imidacloprid, which was increased from lower to highest at first, the second and third weeks of exposures. Patil et al. (2017) showed that second instar Leucopholis lepidophora grubs were more susceptible to infections with nematodes when compared to subsequent insect stages. Wu et al. (2017) concluded that the combination of nematodes and thiamethoxam significantly increases the mortality of Bradysia odoriphaga larvae in comparison to single applications of nematodes and thiamethoxam. They showed that the combination of EPNs with insecticides was most effective $(90 \%)$ for the control of insect pests for up to six weeks. Koppenhofer et al. (2000) stated that the combination of EPNs and imidacloprid has proven fruitful for the control of white grubs showing high compatibility and a low environmental impact. Nematodes applications with insecticides present less hazardous effects on the environment and biotic 
communities. Is our research answerable to a very significant hypothesis that how nematodes applications with combinations of insecticides could improve control strategies used to manage $R$. ferrugineus? Based on our results, time and insect stage appeared the most significant that could affect nematodes efficacies and their combinations with insecticides.

In our second experiment, we tested the effectiveness of EPN and imidacloprid against the adults of $R$. ferrugineus. Our results showed that adult mortality was lower than the mortality of the larval stages; however, it was gradually increasing with increasing concentration and time. In the single treatments, the mortality rate was observed lowest than in the combined treatments. Mbata et al. (2018) explain that nematodes are most virulent to adult maize weevils and caused the highest mortality, which was observed similar in our research against RPW. Rodriguez et al. (2007) showed that Tribolium castaneum larvae, which were treated with Steinernema riobrave, had higher mortality than adult beetles. Which confirms our hypothesis that $R$. ferrugineus increase their immunity levels during their growth and when they reached maturity, they develop effective internal mechanisms to cope with control applications. As compared to $R$. ferrugineus larval stages, time and concentration were also observed most significant factors against the mortality of adults.

We also evaluated the impact of the nematodes and the insecticide on the development of $R$. ferrugineus. Our results showed that pupation rate, adult emergence, and egg eclosion were higher in the nematode treatment than in the insecticide treatment. As compared to individual treatments, pupation rate, adult emergence and egg eclosion were lowest in the combined treatment. The second instar stage showed the lowest pupation rate, adult emergence and egg eclosion in comparison to the fourth and sixth instar. Egg eclosion appeared the most susceptible when compared to pupation rate and adult emergence. Hubner et al. (2017) concluded that the larvae of spotted wing drosophila, Drosophila suzukii when was treated with nematodes showed less adult appearance. Wakil et al. (2017) showed that egg eclosion, pupation rate, and adult emergence was decreased when $R$. ferrugineus larvae were treated with entomopathogenic fungi and nematodes alone and this effect was even higher in the combined treatment. There is a lack of information regarding the effectiveness of combined applications of nematodes and insecticides on adult mortality and the development of $R$. ferrugineus. Our research helps to fill this gap with accurate and significant results. Further investigations are needed that would explain the molecular mechanisms involved in the synergies of nematodes and insecticide applications.

\section{Conclusion}

Biological control is the only way to suppress pest populations without or with minimum applications of chemicals. Entomopathogenic nematodes (EPNs), preferably in combination with insecticides, could provide effective management of pest species, especially the red palm weevil, $R$. ferrugineus. In response to these challenges, the current research was conducted to test the effectiveness of EPN and insecticide alone and in combination. The results showed that the mortality of $R$. ferrugineus larvae and adults was increasing with increasing concentrations. In individual treatments, the $R$. ferrugineus showed less mortality, which was recorded higher in insecticide exposure. However, in nematode-insecticide combinations, $R$. ferrugineus showed a higher mortality rate when compared to single treatments. We also evaluated the effect of EPN and their combinations with insecticide on the development of $R$. ferrugineus. Our results showed that pupation rate, adult emergence and egg eclosion was lower in the combined treatments as compared to the single treatments. In conclusion to our research, EPNs combinations with pesticides could provide effective biological control of $R$. ferrugineus with the advantage of being less hazardous to the environment and human health.

\section{Acknowledgment}

We are also thankful to Lana Dobrindt, Postdoc student at Division of Agricultural Entomology, University of Göttingen, Germany, for reviewing and making grammatical and punctuation corrections in our manuscript. We are thankful to Dr. Muhammad Ishaque Mastoi, Director Plant Protection, at Plant Science Division, PARC, Islamabad, Pakistan, for suggestions and helpful comments regarding our manuscript. I am thankful to all cited authors for honesty and eco-friendly environment during research trials.

Disclaimer: None.

Conflict of Interest: None.

Source of Funding: This research was based on partial funding. The pesticide company Bayer Crop Science, Pvt. Ltd. Pakistan sponsored all chemicals that were used in this study. EPNs were obtained from the nematodes culture in the Microbial Control Laboratory, Department 
of Entomology, University of Agriculture, Faisalabad, Pakistan. The student and supervisor funded other expenses during experiments.

\section{References}

Abraham VA, Shuaibi MA, Faleiro JR, Abuzuhairah RA and Vidyasagar PSPV, 1998. An integrated management approach for red palm weevil, Rhynchophorus ferrugineus Olive. A key pest of date palm in the Middle East. J. Sci. Res. Agric. Sci. 3: 7784.

Ali MP, Bari MN, Haque SS, Kabir MMM, Afrin $\mathrm{S}$, Nowrin $\mathrm{F}$, Islam $\mathrm{MS}$ and Landis DA, 2019. Establishing next-generation pest control services in rice fields: eco-agriculture. Sci. Rep. 9: 10180.

Allan SA, 2018. Behavior-based control of insect crop pests. In: Cordoba-Aguilar, A., Gonzales-Tokman, D., and Gonzalez-Santoyo, I. editors. Insect Behavior. New York, NY: Oxford University Press Mexico. 309$331 \mathrm{pp}$.

Alvarez RP, Nault BA and Poveda K, 2019. Effectiveness of augmentative biological control depends on landscape context. Sci. Rep. 9: 8664.

Atwa AA, 2018. Biological Control Potential of Two Steinernematid Species against the Date Fruit Stalk Borer (Oryctes elegans Prell, Coleoptera: Scarabaeidae). J. Ins. Sci. 18: 26.

Avand FA, 1996. The biology of red palm weevil, Rhynchophorus ferrugineus Oliv. (Coleoptera, Curculionidae) in Saravan region (Sistan \& Balouchistan Province, Iran). App. Ent. Phy. 63: 1618.

Bakera BP, Thomas A, Greenb and Lokerb AJ, 2020. Biological control and integrated pest management in organic and conventional systems. Biol. Control. 140: 104095.

Charnley A and Collins SA, 2007. Entomopathogenic fungi and their role in pest control. In: Howard, D. H. \& Miller J. D. (Eds), the Mycota IV: Environmental and Microbial Relationships, Springer-Verlag, Berlin, Heidelberg, Germany.159-187 pp.

De Faria MR and Wraight SP, 2007. Mycoinsecticides and Mycoacaricides: a comprehensive list with worldwide coverage and international classification of formulation types. Bio. Cont. 43: 237-256.

Delnat V, Tran TT, Janssens L and Stoks R, 2019. Resistance to a chemical pesticide increases vulnerability to a biopesticide: Effects on direct mortality and mortality by predation. Aquat. Toxicol. 216: 105310

Dembilio $\mathrm{O}$ and Jaques JA, 2015. Biology and management of red palm weevil. Springer International Publishing Switzerland. pp. 13-36.

Dembilio O, Llacer E, Martínez MM and Jacas JA, 2010. Field efficacy of imidacloprid and Steinernema carpocapsae in a chitosan formulation against the red palm weevil Rhynchophorus ferrugineus (Coleoptera: Curculionidae) in Phoenix canariensis. Pest Manage. Sci. 66: 365-370.

Dermauw W, Pym A, Bass C, Van T, Leeuwen and Feyereisen R, 2018. Does host plant adaptation lead to pesticide resistance in generalist herbivores? Curr. Opin. Insect. Sci. 6: 25-33.

Erskine W, Moustafa AT, Osman AE, Lashine Z, Nejatian A, Badawi T and Ragy SM, 2004. Date palm in the GCC countries of the Arabian Peninsula. In: Regional Workshop on Date palm Development in the Arabian Peninsula, Abu Dhabi. UAE 29-31 May 2004.

Garriga A, Daniel AM, Fernando GL and Pino G, 2019. Compatibility of entomopathogenic nematodes with natural enemies for horticultural pest control. Bio. Cont. 138: 104050.

Gaugler R, 1988. Ecological considerations in the biological control of soil-inhabiting insects with entomopathogenic nematodes. Agric. Ecosyst. Environ. 24: 351-360.

Hadrami AE and Jameel MAK, 2012. Socioeconomic and traditional importance of date palm. Emi. J. Food Agric. 24: 371-385.

Hubner A, Englert C and Herz A, 2017. Effect of entomopathogenic nematodes on different developmental stages of Drosophila suzukii in and outside fruits. Biol. Control. 62: 669-680.

Hussain A, Haq MRU, Al-Jabr AM and Al-Ayied HY, 2013. Managing invasive populations of red palm weevil: A worldwide perspective. J. Food Agric. Environ. 11: 456-463.

Ju RT, Wang F, Wan FH and Li B, 2011. Effect of host plants on development and reproduction of Rhynchophorus ferrugineus (Olivier) (Coleoptera: Curculionidae). J. Pest Sci. 84: 33-39.

Khamiss O and Abdel BA, 2013. Initiation, characterization and karyotyping of a new cell line from red palm weevil Rhynchophorus ferrugineus adapted at $27^{\circ} \mathrm{C}$. AFPP-Palm Pest Mediterranean Conference, 16-18 January 2013, Nice, France.

Khan S, Guo L, Maimaiti Y, Mijit M and Qiu D, 2012. Entomopathogenic fungi as microbial biocontrol agent. Mol. Plant Breed. 3: 63-79.

Koppenhofer AM, Brown IM, Gaugler R, Grewal PS, Kaya HK and Klein MG, 2000. Synergism of Entomopathogenic Nematodes and Imidacloprid against White Grubs: Greenhouse and Field Evaluation. Biol. Control. 19: 245-251. 
Kurian C and Mathen K, 1971. Red palm weevil hidden enemy of coconut palm. Ind. Farm. 21: 29-31.

Lacey LA and Georgis R, 2012. Entomopathogenic Nematodes for Control of Insect Pests Above and Below Ground with Comments on Commercial Production. J. Nematol. 44: 218-225.

Mashal MM and Obeidat BF, 2019. The efficacy assessment of emamectin benzoate using micro injection system to control red palm weevil. Heliy. 5: e01833.

Mbata GN, Land C and Shapiro-Ilan ID, 2018. The potential for using entomopathogenic nematodes and fungi in the management of the maize weevil, Sitophilus zeamais (Motschulsky) (Coleoptera: Curculionidae). Biol. Control. 125: 39-43.

Nirula KK, 1956. Investigations on the pests of coconut palm. Part 4. Rhynchophorus ferrugineus. Ind. Coc. J. 9: 229-247.

Patil J, Kumar V and Lakshmi RL, 2017. Efficacy of entomopathogenic Heterorhabditis and Steinernema nematodes against the white grub, Leucopholis lepidophora Blanchard (Coleoptera: Scarabaeidae). Crop Prot. 101: 84-89

Pervez R, Eapen SJ, Devasahayam S and Jacob TK, 2012. Efficacy of some entomopathogenic nematodes against insect pests of ginger and their multiplication. Nematol. Mediterr. 40: 39-44.

Poinar GO, 1990.Taxonomy and biology of Steinernematidae and Heterorhabditidae. In: Gaugler, R. \& Kaya H. K. (Eds), Entomopathogenic Nematodes in Biological Control. CRC Press, Boca Raton, Florida, USA. pp. 23-61.

Portman SL, Sindhu MK and Gadi VPR, 2016. Entomopathogenic Nematodes Combined with Adjuvants Presents a New Potential Biological Control Method for Managing the Wheat Stem Sawfly, Cephus cinctus (Hymenoptera: Cephidae). PLoS One. 11: e0169022.

Rajamanickam K, Kennedy JS and Christopher A, 1995. Certain components of integrated management for red palm weevil, Rhynchohphorus ferrugineus F. (Curculionidae: Coleoptera) on coconut. Mede. Facu. Land. Toe. Biol. Weten. 60, 803-805.

Rodriguez OR, James FC and Sonny BR, 2007. Efficacy of the entomopathogenic nematode Steinernema riobrave against the stored-product insect pests Tribolium castaneum and Plodia interpunctella. Biol. Control. 40: 15-21.

Rovesti L and Deseo KV, 1990. Compatibility of Chemical Pesticides with the Entomopathogenic Nematodes, Steinernema Carpocapsae Weiser and S. Feltiae Filipjev (Nematoda: Steinernematidae). Nematol. 36: 237-245.
Thurston GS, Kaya HK and Gaugler R, 1994. Characterization of enhanced susceptibility of milky disease infected scarabaeid grubs toentomopathogenic nematodes. Biol. Control. 4: 67-73.

Wakil W, Faleiro JR and Miller TA, 2015. Sustainable pest management in Date Palm: Current status and emerging challenges, sustainability in plant and crop protection. Springer International Publishing Switzerland. p. 445.

Wakil W, Yasin M and Shapiro-Ilan D, 2017. Effects of single and combined applications of entomopathogenic fungi and nematodes against Rhynchophorus ferrugineus (Olivier). Sci. Rep. 7: 5971.

Wu H, Gong Q, Fan K, Sun R, Xu Y and Zhang K, 2017. Synergistic effect of entomopathogenic nematodes and thiamethoxam in controlling Bradysia odoriphaga Yang and Zhang (Diptera: Sciaridae). Biol. Control. 111: 53-60.

Yadav AK and Lalramliana, 2012. Efficacy of indigenous entomopathogenic nematodes from Meghalaya, India against the larvae of taro leaf beetle, Aplosonyx chalybaeus (Hope). J. Para. Dis. 36: 149-154.

Yan TK, Asari A, Abdullah S, Ismail M and Azmi WA, 2019. The dataset for antifeedant activity of eugenol derived compounds against red palm weevil (Rhynchophorus ferrugineus, Olivier) larvae. Data Brief. 25: 10422.

Yan X, Moens M, Han R, Chen S and Clercq PD, 2012. Effects of selected insecticides on osmotically treated entomopathogenic nematodes. J. Plant Dis. Prot. 119:152-158.

Yuksel E, Canhilal R and MustafaImren, 2019. Potential of four Turkish isolates of entomopathogenic nematodes against three major stored products insect pests. J. Stored Prod. Res. 83: 317-321.

\section{Contribution of Authors}

Arshad A: Data collection and manuscript writing Munawar A: Data collection and manuscript writing

Mastoi MI: Designed experiments and provided the material required

Sohail S: Designed experiments and provided the material required

Bashir F: Designed experiments and provided the material required

Liang C: Designed experiments and provided the material required 